\title{
PERCEPÇÃO DE IMPACTOS SOBRE A PESCA ARTESANAL: CAMINHOS PARA O MANEJO DOS RECURSOS PESQUEIROS DO AMAPÁ, BRASIL
}

\author{
PERCEPTION OF IMPACTS ON ARTISANAL FISHING: PATHS FOR THE \\ MANAGEMENT OF FISHING RESOURCES IN AMAPÁ, BRAZIL
}

\author{
Wanderson Michel de Farias PANTOJA ${ }^{1 *}$; Jacklinne Matta CORRÊA ${ }^{2}$; Simone Dias FERREIRA ${ }^{3}$; Glenda de \\ Freitas GUEDES ${ }^{3}$; Renan Pereira MENDONÇA ${ }^{3}$; Jair de Farias PANTOJA ${ }^{3}$. \\ ${ }^{1}$ Programa de Pós-Graduação em Ecologia Aquática e Pesca, Universidade Federal do Pará, Belém, Pará, Brasil. ${ }^{2}$ Universidade Federal do \\ Amapá, Curso de Ciências Ambientais, Macapá, Amapá, Brasil. ${ }^{3}$ Universidade do Estado do Amapá, Curso de Engenharia de Pesca, \\ Macapá, Amapá, Brasil. \\ *wanderson.pantoja@ifap.edu.br
}

\section{RESUMO}

Este estudo analisou o conhecimento de pescadores artesanais sobre aspectos ecológicos e de percepção ambiental da atividade pesqueira artesanal de comunidades componentes de duas Bacias Hidrográficas do estado do Amapá. Foi adotada uma amostragem do tipo "bola de neve" que resultaram em entrevistas com 87 pescadores no período de junho de 2015 a junho de 2017. Os pescadores apresentaram considerável tempo de atividade na pesca $(20,8 \pm 13,4$ anos $)$ e mostraram ter vasto conhecimento ecológico e percepção ambiental considerável quanto aos recursos pesqueiros da região. A percepção sobre a abundância e a diminuição de espécies de diferentes etnoespécies de peixes nas duas áreas de estudo apresentou diferenças. Foi registrada a redução de estoques pesqueiros e o aumento de outras espécies nas comunidades componentes da Bacia Hidrográfica do Rio Curiaú (Hoplias sp.; Hoplosternum litrorale) e na bacia do Igarapé Fortaleza (Plagioscion sp.; Hoplias sp.). Os problemas ambientais apontados como mais preocupantes para a atividade pesqueira foram: o tráfego de barcos; poluição do rio; óleo despejado na água; lago secando; diminuição de peixes e presença de búfalos. Este estudo apontou informações pioneiras para o estado do Amapá, a exemplo de que houve redução de estoques pesqueiros e aumento da ocorrência de espécies. Esses resultados podem orientar estudos futuros para coleta de peixes, mitigação de impactos e estratégias de educação ambiental. Esse conhecimento ecológico local precisa ser conservado e pode contribuir para aplicação de estratégias de manejo e co-manejo dos recursos pesqueiros da região para melhorar a gestão da atividade de pesca artesanal.

PALAVRAS-CHAVE: Conhecimento local, Ecologia, Redução de estoques, Diversidade, conservação.

\footnotetext{
ABSTRACT

This study analyzed the knowledge of artisanal fishermen about ecological aspects and environmental perception of artisanal fishing activity in communities that are part of two hydrographic basins in the state of Amapá. A "snowball" sampling was adopted, which resulted in interviews with 87 fishermen from June 2015 to June 2017. The fishermen had considerable activity time in fishing $(20.8 \pm 13.4$ years $)$ and showed have extensive ecological knowledge and considerable environmental awareness of the region's fisheries resources. The perception of the abundance and decrease of species of different ethnospecies of fish in the two study areas showed
} 
PANTOJA et al. Percepção de impactos sobre a pesca artesanal: caminhos para o manejo dos recursos pesqueiros do Amapá, Brasil. Ethnoscientia v.6 n. 1, 2021. DOI: 10.22276/ethnoscientia.v6i1.355

differences. There was a reduction in fish stocks and an increase in other species in the communities comprising the Curiaú River Basin (Hoplias sp.; Hoplosternum litrorale) and in the Igarapé Fortaleza basin (Plagioscion sp.; Hoplias sp.). The environmental problems identified as most worrying for fishing activity were: boat traffic; river pollution; oil poured into water; drying lake; decrease in fish and presence of buffalo. This study pointed out pioneering information for the state of Amapá, for example that there was a reduction in fish stocks and an increase in the occurrence of species. These results can guide future studies for collecting fish, mitigating impacts and environmental education strategies. This local ecological knowledge needs to be conserved and can contribute to the application of management strategies and co-management of the region's fisheries resources to improve the management of artisanal fisheries.

KEYWORDS: Local knowledge, Ecology, Inventory reduction, Diversity, Conservation.

\section{INTRODUÇÃO}

Estudos sobre a percepção ambiental têm buscado compreender como os aspectos ambientais podem influenciar os indivíduos de forma conjunta ou individualmente. Esses estudos também buscam entender o indivíduo em relação as suas ações, sentidos e emoções de satisfação e insatisfação com o que percebem. Permitindo então, a mensuração e avaliação do ambiente em que os indivíduos atuam, além do direcionamento de suas atividades com aplicação de alternativas viáveis ao olhar das populações locais em conjunto com as instituições que promovem as políticas públicas ambientais e a gestão dos recursos naturais (MELAZO, 2005; OLIVEIRA \& CORONA, 2008; COSTA \& COLESANTI, 2011).

Nesse sentido, uma alternativa de melhor gestão dos recuros naturais tem sido estudada por muitos autores como sistemas de gestão compartilhada, comanejo, cogestão ou cogerenciamento, que são reconhecidos mundialmente como uma alternativa viável para a efetiva participação de ambos, governo e usuários, na administração da pesca, além de ser um caminho para a descentralização do gerenciamento pesqueiro (PINKERTON, 2003; POMEROY \& BERKES, 1997; WILSON et al., 2003).

Atualmente, os ambientes de água doce estão sofrendo grandes alterações nos estoques naturais de peixes devido, principalmente, à intensificação das atividades antrópicas, à valoração econômica atribuída aos recursos pesqueiros e à crescente demanda por alimento (JUNK et al., 2007, CASTELLO et al., 2013). Estudos têm notificado sobre uma grande preocupação com a redução de estoques pesqueiros em consequência da sobrepesca, que além de reduzir as oportunidades de exploração da diversidade aquática, pode ocasionar problemas genéticos para as populações de peixes com a redução do tamanho e do ciclo de vida (HELFMAN et al., 2010). 
PANTOJA et al. Percepção de impactos sobre a pesca artesanal: caminhos para o manejo dos recursos pesqueiros do Amapá, Brasil. Ethnoscientia v.6 n. 1, 2021. DOI: 10.22276/ethnoscientia.v6i1.355

Os impactos ao meio ambiente podem causar desequilíbrio ecológico, de modo que em muitos estudos de ciências pesqueiras, as causas de impactos e os impactos ambientais mais comumente observados são: poluição, eutrofização, assoreamento, construção de barragens, drenagem de áreas alagadas, desmatamento, erosão do solo, pecuária intensiva, pesca predatória e introdução de espécies não nativas, especialmente devido a aquicultura (TUNDISI, 2003; AGOSTINHO et al., 2005). Esses fatores contribuem de forma significativa para a diminuição da diversidade de peixes em ecossistemas fluviais (TUNDISI, 2003; AGOSTINHO et al., 2005; JUNK et al., 2007, CASTELLO et al., 2013).

No estado do Amapá, além dos impactos já citados, inclui-se a atividade de pecuária bubalina extensiva, que é responsável atualmente por danos irreparáveis à biodiversidade aquática e ao uso dos recursos pesqueiros, como a abertura de canais que se estendem constantemente, ocasionando a ligação dos corpos aquáticos, lagos, rios e igarapés, comprometendo a dinâmica da biota local quanto ao seu habitat e reprodução (MEIRELLES \& MOCHIUTTI, 2000). Esses impactos são refletidos na dinâmica de uso dos recursos pesqueiros das comunidades componentes das bacias hidrográficas do rio Curiaú e do Igarapé Fortaleza e o conhecimento ecológico local acerca da percepção de impactos precisa ser estudado e registrado, visto que o não reconhecimento e a ausência de legitimidade do conhecimento dessas populações locais são um indicativo do preconceito quanto ao papel que elas podem exercer para o manejo compartilhado dos recursos naturais (KALIKOSKI, 2002; KALIKOSKI \&VASCONCELLOS, 2007).

Contudo, sabe-se que as informações mais atuais existentes sobre o meio biótico, meio abiótico e meio antrópico das áreas úmidas "ressacas" de Macapá ainda se encontram limitadas ao diagnóstico realizado por Takyama e Silva (2004) que estabelece uma caracterização socioeconômica das áreas de ressaca existentes na região. Assim, deve-se dar a devida importância do conhecimento ecológico local dos pescadores e considerar a representatividade para o estado do Amapá das comunidades humanas residentes nas Bacias do Rio Curiaú-B.H.R.C e Igarapé Fortaleza-B.H.I.F.

\subsection{A pesca artesanal}

O número de pescadores artesanais distribuídos pelo mundo consiste em torno de 40 milhões e essa forma de pesca é realizada por aproximadamente $90 \%$ do total de pescadores no mundo. Assim, é clara a importância econômica, socioambiental e cultural que esta modalidade de atividade pesqueira ostenta (DIEGUES, 2004; BEGOSSI, 2004; BATISTA et al., 2011). Estima-se que aproximadamente $90 \%$ de todas as pessoas que dependem 
PANTOJA et al. Percepção de impactos sobre a pesca artesanal: caminhos para o manejo dos recursos pesqueiros do Amapá, Brasil. Ethnoscientia v.6 n. 1, 2021. DOI: 10.22276/ethnoscientia.v6i1.355

diretamente da pesca extrativa no Brasil trabalham no setor de pequena escala (FAO, 2017). No Brasil, as estimativas mostram que mais de um milhão de pessoas dependem direta ou indiretamente da pesca artesanal nos ambientes marinhos e continentais, pesca essa realizada por comunidades costeiras e ribeirinhas e que se constitui como importante fonte de alimento e renda para essas populações (DIEGUES, 2004; SILVANO, 2004; SANTOS \& SANTOS, 2005; FREITAS \& RIVAS, 2006).

A diversidade e abundância de peixes na Amazônia faz do pescado a principal fonte proteica consumida pelas populações da região, sendo esse consumo maior especificamente, para as comunidades que vivem às margens dos Rios e lagos que compõem os ecossistemas aquáticos da região (ISAAC et al., 1993; 2006; ISAAC \& ALMEIDA, 2011). No Brasil, a Amazônia contribui com uma grande parcela da pesca, tanto em riqueza de espécies exploradas quanto em consumo de pescado pela população local. Na região amazônica, a pesca artesanal ocorre em pequena escala, empregando várias combinações de métodos de pesca, que são desenvolvidos de acordo com os diferentes recursos, ambientes e estações do ano (PETRERE, 1990; MISUND et al., 2002; HALLWASS \& SILVANO, 2016).

O modelo de pesca artesanal, também chamada de pesca tradicional, caracteriza-se por ser praticada em pequenos núcleos familiares, que vivem nas comunidades e tem em sua cultura, crença e religião uma forte ligação com o ambiente natural. Em geral, na Amazônia, esses grupos estão localizados em regiões costeiras, estuários e às margens de rios e lagos. Os métodos e os conhecimentos necessários para realizar a atividade da pesca, assim como a sua cultura em geral, são repassados de geração para geração (ISAAC et al., 1993; BATISTA et al., 2004). Essa prática pesqueira se dá em uma variedade de ecossistemas e isso influencia na forma como as atividades de pesca são organizadas, pois, na execução de suas tarefas diárias, os pescadores devem considerar uma série de fatores, entre os quais estão as correntes marítimas, ventos, maré, ondas, vegetação, fauna, flora e ciclos ecológicos que variam de região para região (PETRERE, 1978; MERONA, 1993; DIEGUES, 2004).

A pesca artesanal, além de fornecer emprego para muitas populações humanas, fornece alimento, visto que a maioria do pescado proveniente dessa atividade é consumido principalmente nos países tropicais e em desenvolvimento, como o Brasil (ISAAC et al., 1993; SILVANO, 2004; MURRIETA et al., 2008; ISAAC \& ALMEIDA 2011). Por outro lado, estudos tem evidenciado impactos da pesca artesanal, e esses impactos vão além das espécies alvo e ocorrem em diferentes níveis em ambientes de água doce, ampliando a 
PANTOJA et al. Percepção de impactos sobre a pesca artesanal: caminhos para o manejo dos recursos pesqueiros do Amapá, Brasil. Ethnoscientia v.6 n. 1, 2021. DOI: 10.22276/ethnoscientia.v6i1.355

necessidade de abordagens mais especificas para o diagnóstico da realidade local, oportunizando assim, a gestão da pesca (BEGOSSI, 1995; MANESCHY, 1995; FURTADO, 1997; SCHREIBER, 2001; FERREIRA \& CARAMASCHI, 2005; ZAPPES et al., 2013; BELTRÃO et al., 2017). A redução na abundância das espécies de maior porte e sua substituição por espécies menores já foi identificada em estudos sobre a pesca artesanal na Amazônia Brasileira (CASTELLO et al. 2013), afetando a seletividade e a composição dos desembarques pesqueiros em diferentes regiões da Amazônia (HALLWASS \& SILVANO, 2016).

\subsection{Conhecimento local de pescadores sobre a ecologia de peixes}

Conceitos prévios segundo Marques (1995) e Johnson (2002), definiram a Etnoictiologia como a busca da compreensão do fenômeno de interação entre o homem e os peixes, englobando aspectos tanto cognitivos quanto comportamentais. No entanto, na atualidade, muitos estudos têm conceituado e relatado a importância do conhecimento ecológico local aliado à conservação de diversos tipos de ambientes, incluindo os ecossistemas aquáticos. Esses estudos têm fornecido novas informações biológicas/ecológicas sobre vários grupos de organismos aquáticos, incluindo os peixes (SILVANO et al., 2008; SILVANO \& VALBO-JORGENSEN 2008; BEGOSSI \& SILVANO, 2008; HALLWASS et al., 2013). Estudos têm apontado que o conhecimento popular pode ser ameaçado pelo desaparecimento de populações locais e de costumes tradicionais, bem como devido ao processo de urbanização, que pode afetar o modo de vida das populações locais (JOHANNES 1978; POSEY 1983; WESTER \& YONGVANIT, 1995; SILVANO \& BEGOSSI, 2002; PEZZUTI et al., 2004). Sabe-se que as populações locais possuem técnicas próprias de uso e manejo dos recursos naturais, através das quais podem interferir no processo de sucessão ecológica, na promoção e regeneração de áreas degradadas, na ciclagem de nutrientes e no aumento da riqueza de espécies em ecossistemas manejados (POSEY 1983, 1984; MORIN- LABATUT \& AKATAR 1992; BALÉE, 1994).

Dessa forma, tendo em vista a valorização da ecologia humana, muitos conhecimentos tradicionais têm sido usados para a elaboração de hipóteses testáveis em diversas pesquisas zoológicas/ecológicas sobre os recursos pesqueiros, dentre as quais estão: etnotaxonomia de peixes, hábitos alimentares, interações tróficas, habitats, locais de pesca, migração, reprodução, impactos ambientais sobre a atividade pesqueira de pequena escala e ecologia de peixes ligada à gestão pesqueira (BEGOSSI \& GARAVELLO, 1990; MARQUES, 1991, SILVANO et al., 2008; BEGOSSI et al., 2008; SILVANO \& VALBO- 
PANTOJA et al. Percepção de impactos sobre a pesca artesanal: caminhos para o manejo dos recursos pesqueiros do Amapá, Brasil. Ethnoscientia v.6 n. 1, 2021. DOI: 10.22276/ethnoscientia.v6i1.355

JORGENSEN, 2008; SILVANO \& BEGOSSI, 2012; HALLWASS et al., 2013). Assim, o conhecimento das interações homem-ambiente, incluindo o conhecimento ecológico local dos pescadores, pode ser usado como subsídio na formulação de programas de manejo e de estratégias de comanejo dos recursos pesqueiros (SEIXAS \& BEGOSSI, 2001; SILVANO \& BEGOSSI, 2012).

$\mathrm{Na}$ Amazônia, estudos etnoictiológicos têm contribuído de várias formas, a saber, para a análise da legislação pesqueira referente a piracema de espécies, em planos de manejo e gestão de unidades de conservação, resolução de conflitos de pesca, além de identificar padrões de impactos ocasionados por barragens sobre a dinâmica de migração dos peixes e a pesca de comunidades locais (BEGOSSI et al., 1999; DORIA et al., 2008; BEGOSSI et al., 2008; SILVANO et al., 2008; BARBOZA \& PEZZUTI, 2011; HALLWASS et al., 2013; 2015; SANTOS et al., 2014).

\subsection{A atividade pesqueira no estado do Amapá}

Autores evidenciam que o Amapá é detentor de uma atividade extrativista pesqueira de natureza fundamentalmente artesanal e pouco competitiva, característica essa atribuída principalmente pela incapacidade da frota pesqueira amapaense de superar as capturas realizadas por embarcações de outros estados. No entanto, o Amapá apresenta vantagem quanto à comercialização do pescado em razão de sua localização geográfica, considerada estratégica para o escoamento da produção aos principais mercados consumidores da Europa, entre outros continentes (BATISTA et al., 2004; SILVA \& SILVA, 2006; SILVA \& TAVARES-DIAS, 2010).

Quanto às áreas de desenvolvimento da atividade pesqueira do Amapá, a pesca é desenvolvida em ambientes aquáticos distintos, sendo executada em áreas de planície marítima, região dos lagos, baixo estuário, braços de rio e igarapés componentes de áreas urbanas e portuárias e na região do alto estuário (SUFRAMA, 1999). Sabe-se que a atividade pesqueira no Estado tem grande potencial em função da descarga de água doce pelo Rio Amazonas e seus afluentes, que proporcionam um ambiente de elevada produtividade primária, favorecendo a ocorrência de diversas espécies de peixes e crustáceos, os quais constituem recursos naturais de grande importância para as pescas artesanal e industrial no litoral norte-atlântico (MINISTÉRIO DO MEIO AMBIENTE, 1997, 2006; ISAAC-NAHUM, 2006). No entanto, a proximidade do Oceano Atlântico com a costa da Amazônia Oriental-Amapá não é suficiente para a captura de espécies marinhas, logo, a influência do Rio Amazonas é responsável por manter o nível baixo de salinidade da 
PANTOJA et al. Percepção de impactos sobre a pesca artesanal: caminhos para o manejo dos recursos pesqueiros do Amapá, Brasil. Ethnoscientia v.6 n. 1, 2021. DOI: 10.22276/ethnoscientia.v6i1.355

água, proporcionando abundância de espécies de água doce com grande valor de mercado, como por exemplo, Pirarucu (Arapaima gigas), Tamoatá (Hoplosternum sp.), Mandubé (Ageneiosus spp.), Tucunaré (Cichla spp.), Aruanã (Osteoglossum bicirrhosum), Apaiari (Astronotus ocellatus), Traíra (Hoplias spp.) entre outras (SILVA, 2014). Contudo, o Estado do Amapá ainda precisa avançar em estudos etnoicticológicos, sendo poucos os estudos com abordagens etnoecológicas, pois além da existência de uma grande diversidade de espécies da fauna e flora possui também grande legado da sociobiodiversidade representativa na Amazônia.

\subsection{Características de qualidade Ambiental da Área de estudo}

As comunidades componentes das duas Bacias Hidrográficas em estudo, foram escolhidas pela facilidade de acesso e proximidade com os ambientes aquáticos (pesqueiros) da região. Essas comunidades possuem diferenças socioambientais e culturais na qual diferenças na atividade pesqueira podem existir. Existem características culturais, de ancestralidade, religiosas que as distinguem e, consequentemente, o conhecimento etnoecológico pode refletir caracteristicas peculiares de uso dos recursos naturais por parte dos sujeitos.

A Bacia Hidrográfica do Igarapé Fortaleza, Macapá, lida constantemente com as ações antrópicas (TAKIYAMA, 2004; SANTOS, 2006). As áreas úmidas, conhecidas como áreas de ressaca, estão localizadas em quase todo o perímetro urbano, o que facilita o acesso e consequentemente a degradação ambiental deste habitat pelo processo de urbanização (TAKIYAMA et al., SILVA et al., 2004). Essas áreas estão sofrendo uma rápida e desordenada ação de ocupação humana, levando a uma acelerada degradação ambiental, configurando assim um indicador de estresse ao meio biótico, que pode interferir na vida dos peixes. Ao redor da bacia estão instaladas concessionárias automobilísticas, faculdades, conjuntos habitacionais e loteamentos que, eventualmente, lançam produtos industriais e/ou esgoto sem nenhum tipo de tratamento dentro do ecossistema (NERI, 2004).

Nas comunidades componentes da Bacia Hidrográfica do Rio Curiaú, a economia se baseia na agricultura de subsistência, na pecuária extensiva, no extrativismo vegetal e na pesca (FACUNDES, 2000). A pesca nos corpos aquáticos do Curiaú é uma das atividades mais afetadas pelas mudanças sociais e ecológicas, pois da abundância de anos anteriores, há muito tempo se percebe a perda de espécies de peixes e redução de cardumes (QUEIROZ, 2007). Para analisar as diferenças entre as duas áreas de estudo, primeiramente tem-se que considerar o objetivo central de uma APA, Área de Proteção Ambiental que é a 
PANTOJA et al. Percepção de impactos sobre a pesca artesanal: caminhos para o manejo dos recursos pesqueiros do Amapá, Brasil. Ethnoscientia v.6 n. 1, 2021. DOI: 10.22276/ethnoscientia.v6i1.355

conservação de processos naturais e da biodiversidade, através da orientação, do desenvolvimento e da adequação das várias atividades humanas às características ambientais da área. Nesse sentido este trabalho buscou analisar a percepção de pescadores sobre as alterações ambientais, a abundância de peixes e o ecossistema em geral, na busca de propor estratégias de manejo e comanejo a partir da ótica do pescador artesanal, oportunizando a conservação dos estoques pesqueiros e consequentemente do conhecimento local, procurando promover a reprodução e desenvolvimento sustentável dos recursos pesqueiros locais.

\section{MATERIAL E MÉTODO}

\subsection{Caracterização da área de estudo e ictiofauna estudada}

De acordo com dados de Takiyama \& Silva, (2004) o estado do Amapá (Figura 1) possui posição estratégica em termos geográficos, características climáticas, hidrológicas e de vegetação peculiares entre as regiões equatoriais. Entre as 39 Bacias Hidrográficas existentes no estado, a bacia hidrográfica do Rio Curiaú possui 584,47 $\mathrm{Km}^{2}$ (Figura 1) e dentro da sua área de extensão está o território quilombola do Curiaú, que abriga aproximadamente 165 famílias (FACUNDES \& GIBSON, 2000). Por outro lado, a área correspondente à Bacia Hidrográfica do Igarapé Fortaleza possui $193 \mathrm{~km}^{2}$ de área e abriga a maior parte das duas principais cidades do estado, Macapá (Capital) e Santana (Figura 1). A população estimada em 2009 pelo Instituto Brasileiro de Geografia e Estatística (IBGE, 2010) vivendo nesta bacia era de aproximadamente 463 mil habitantes, o que equivale a uma densidade populacional de $2239 \mathrm{hab} / \mathrm{km}^{2}$. No entanto, dados obtidos pelos moradores para este estudo mostram considerável crescimento. 


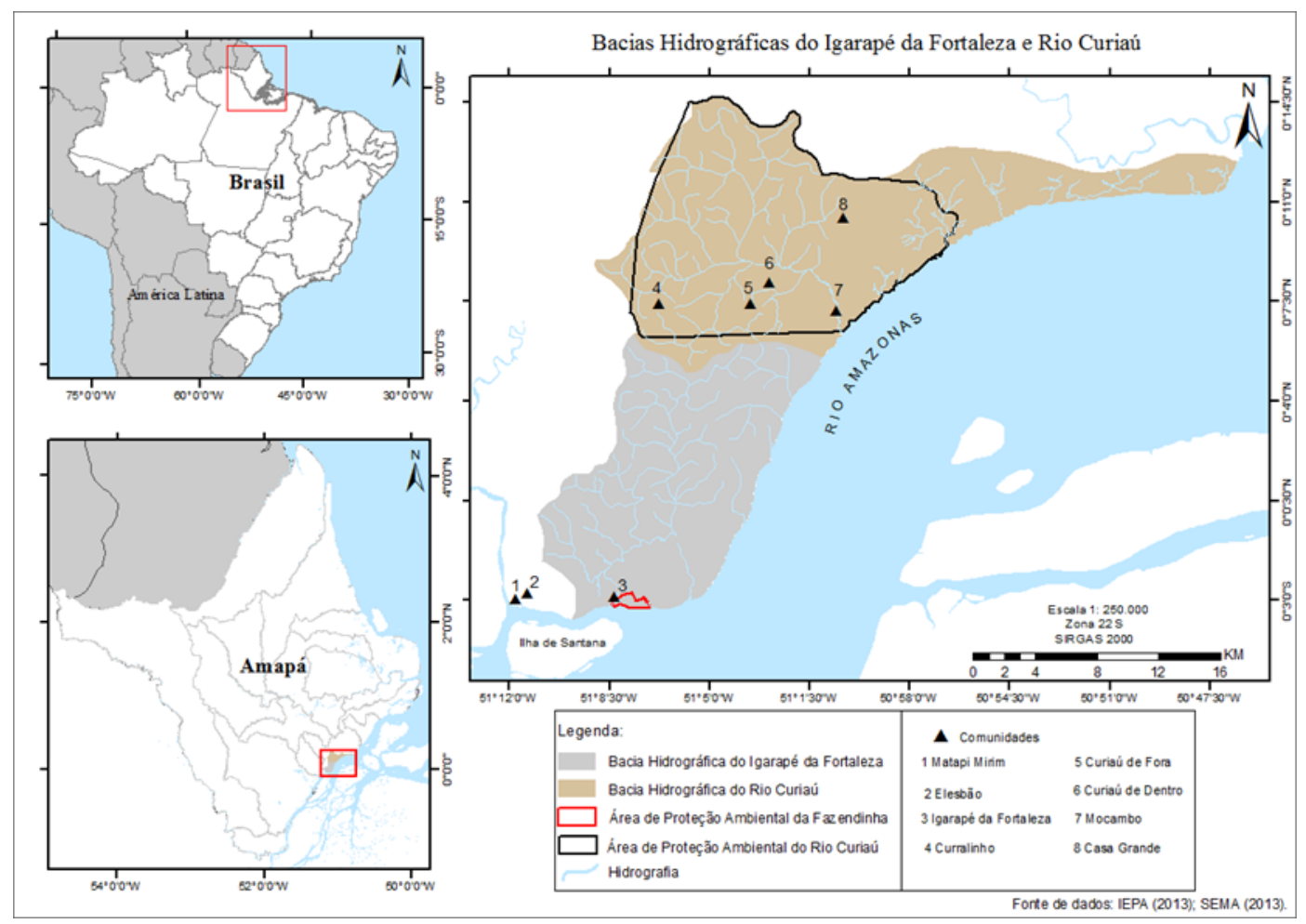

Figura 1: Localização das comunidades componentes das áreas de estudo da bacia hidrográfica do Igarapé Fortaleza (Elesbão; Matapi-Mirim; Igarapé da Fortaleza) e Bacia Hidrográfica do Rio Curiaú (Curralinho; Mocambo; Curiaú de fora; Curiaú de dentro; Casa Grande), Amapá, Amazônia Oriental, Brasil. (Fonte: IEPA, 2013; SEMA, 2013).

\subsection{Coleta de dados e análise dos dados}

Foi proposta uma pesquisa voltada para o conhecimento acumulado pela parte da população que trabalha semanalmente com a pesca artesanal, conforme metodologia adotada em outros estudos etnoictiológicos (SILVANO et al., 2004, 2006). Foi adotada a amostragem do tipo bola de neve "snowball sampling" na qual alguns informantes foram previamente identificados, sob a orientação do representante comunitário e após serem entrevistados, foram solicitados a indicar novos possíveis informantes para a pesquisa (ALBUQUERQUE \& LUCENA 2004; ANDRADE et al., 2006; BAILEY, 1994; SILVANO \& BEGOSSI, 2001; SILVANO et al., 2006, 2008). Nesse sentido, a amostragem foi considerada suficiente com base no efeito de uma inclusão progressiva, que permita aplicar o critério da exaustividade (BERNARD, 2005). Foram realizadas entrevistas individuais acompanhadas previamente do Termos de Consentimento Livre e Esclarecido (TCLE) como preconiza a Resolução CNS 466/12). Este termo foi orientado e por todos os participantes em respeito a questão ética da pesquisa com seres humanos. Os formulários semiestruturados foram aplicados a pescadores de oito 
PANTOJA et al. Percepção de impactos sobre a pesca artesanal: caminhos para o manejo dos recursos pesqueiros do Amapá, Brasil. Ethnoscientia v.6 n. 1, 2021. DOI: 10.22276/ethnoscientia.v6i1.355

comunidades componentes das duas bacias hidrográficas em estudo, sendo na Bacia Hidrográfica do Rio Curiaú ( 5 comunidades) e Bacia Hidrográfica do Igarapé Fortaleza (3 comunidades) no período de junho de 2015 a junho de 2017. Essas comunidades foram escolhidas de acordo com a proximidade dos corpos aquáticos, na qual a atividade pesqueira artesanal acontece na região de estudo, sendo entrevistado um pescador por domicílio, de acordo com metodologia proposta por Viertler (2002).

O formulário incluiu perguntas fechadas e abertas sobre o perfil socioeconômico, bem como perguntas sobre o conhecimento dos pescadores a respeito de apetrechos, iscas e as respectivas espécies de peixes capturadas, bem como os impactos ambientais na atividade pesqueira. Cada formulário aplicado foi acompanhado de um caderno de fotos correspondendo a kits fotográficos de peixes comumente encontrados na região, a fim de aproveitar a visualização para melhor identificação dos organismos pelo pescador, possibilitando assim avaliar os conhecimentos dos pescadores ligados à ecologia e a percepção ambiental das diferentes espécies e os termos regionais utilizados para identificar e nomear os peixes e os problemas ambientais locais de acordo com procedimentos metodológicos de estudos pregressos (GIL, 1999; MINAYO, 1992, 1994; CARDOSO, 1986; AMOROZO, 1996; BEGOSSI et al., 2008).

\subsection{Processamento e análise dos dados}

Os dados quantitativos e qualitativos foram tabulados em planilhas eletrônicas. As análises dos dados quantitativos do conhecimento dos pescadores das comunidades componentes de cada Bacia Hidrográfica estudada resultaram na aplicação da estatística descritiva (média, mediana e desvio padrão) usando o Software BioEstat 5.0. Os dados quantitativos e qualitativos das respostas das entrevistas sobre a percepção ambiental acerca da abundância de peixes (peixes que diminuíram em abundância, peixes que aumentaram em quantidade, e os possíveis motivos das variações na abundância) foram quantificados em frequências (porcentagem de pescadores que mencionaram) e comparados entre os pescadores das duas bacias, as frequências de percepção ambiental referentes a conservação ambiental e a redução no estoque de peixes foram analisadas através do teste qui-quadrado $\left(\chi^{2}\right)$ seguido pela correção de Yates para indicar as respostas mais citadas e as frequências mais representativas (ZAR, 2010; HALLWASS et al., 2013).

Os trechos dos áudios registrados com a permissão dos entrevistados foram transcritos diretamente na ordem de abordagem dos respectivos temas e analisados qualitativamente em comparação a estudos científicos similares, afim de estabelecer 
PANTOJA et al. Percepção de impactos sobre a pesca artesanal: caminhos para o manejo dos recursos pesqueiros do Amapá, Brasil. Ethnoscientia v.6 n. 1, 2021. DOI: 10.22276/ethnoscientia.v6i1.355

comparações entre as informações provenientes do saber local (obtidas durante as entrevistas) e aquelas encontradas em estudos ecológicos sobre os mesmos temas. Os impactos ambientais observados pelos pescadores e as alternativas de mitigação/reparação/compensação apontadas por eles, foram organizados em uma tabela de percepção ambiental, que buscou organizar o discurso direto e indireto dos sujeitos sobre esse aspecto da percepção ambiental local.

\section{RESULTADOS E DISCUSSÃO}

Foram entrevistados 87 pescadores residentes em oito comunidades nas duas áreas de estudo correspondentes a Bacia Hidrográfica do Igarapé Fortaleza e Bacia Hidrográfica do Rio Curiaú. A análise das entrevistas dos pescadores das comunidades apresentaram padrões similares quanto a percepção dos pescadores sobre conservação ambiental, quando questionados sobre o que é conservação ambiental, foram registradas diferentes frequências de respostas correspondentes aos conceitos aplicados à conservação ambiental, 98 \% e 82,3 $\%$ respectivamente para B.H.R.C $\left(\chi^{2}=65,0 \mathrm{p}=0,0001\right)$ e B.H.I.F, sendo relatados por eles, aspectos gerais sobre "Preservar e conservar o meio ambiente" ( $n=41$ citações de pescadores), seguindo a linha de argumentação secundária que refere-se à "Conservação das espécies no período de defeso" ( $n=23$ citações de pescadores) e em terceiro a citação de "Não poluir o meio ambiente" ( $\mathrm{n}=11$ pescadores) como componentes formadores do entendimento sobre conservação ambiental. A percepção sobre a abundância de recursos pesqueiros nas duas áreas apresenta diferenças, sendo observada diferença nas frequências citadas (Tabela 1) sendo maior essa percepção para as comunidades da B.H.I.F $\left(\chi^{2}=127,0\right.$ $\mathrm{p}=0,0001)$.

Na Bacia Hidrográfica do Igarapé Fortaleza, os pescadores artesanais, quando questionados sobre a percepção de alterações ambientais em seu ambiente de pesca (pesqueiros), citaram uma grande diversidade de alterações percebidas, sendo as mais frequentes: o tráfego de barcos de diferentes tipos que ocasiona barulho e espanta os peixes (26\%), a poluição do rio através do acumulo de lixo despejado pelos moradores próximos (11\%) e o óleo das embarcações que se acumula na água (11\%) (Tabela 2), outros 52\% citaram diferentes alterações e impactos percebidos, sendo estes: o desmatamento, assoreamento, conflitos de pesca, arrastos, aumento do número de pessoas pescando nos pesqueiros da região e a erosão do Rio.Estudos nas comunidades dessa Bacia Hidrográfica mostram que essa área sofre constantemente com ações antrópicas, sendo possível relacionar as citações dos moradores com impactos sobre a poluição dos corpos aquáticos, 
PANTOJA et al. Percepção de impactos sobre a pesca artesanal: caminhos para o manejo dos recursos pesqueiros do Amapá, Brasil. Ethnoscientia v.6 n. 1, 2021. DOI: 10.22276/ethnoscientia.v6i1.355

que pode alterar a qualidade e o equilíbrio do meio ambiente (TAKIYAMA, 2004; SANTOS, 2006).

No entanto, alterações relacionadas ao tráfego de embarcações em maior número, óleo despejado nos corpos aquáticos, desmatamento, assoreamento, conflitos de pesca, arrastos, aumento do número de pessoas pescando nos pesqueiros da região e a erosão do rio são impactos registrados pela primeira vez sob a ótica dessas populações locais. Por outro lado, na B.H.R.C, quando questionados da mesma forma, as citações mais frequentes foram as modificações na paisagem, sendo apontados: o lago e Rio secando e/ou ficando cada vez mais raso, demorando a encher no período de inverno $(23 \%)$, diminuição do número de peixes (19\%), presença de búfalos (19\%) (Tabela 2) e assoreamento (4\%).

Estudos na região têm apontado que um dos principais efeitos do conflito socioambiental em relação ao uso dos recursos hídricos nessa região tem sido a substituição da atividade de pescar das famílias pela compra do pescado nas feiras de Macapá, bem como as atividades agropecuárias mal planejadas nessas áreas que modificam a paisagem, substituindo a vegetação nativa por extensas áreas agrícolas e que consequentemente comprometem a dinâmica natural do ecossistema aquático pela influência do desmatamento, ocasionando frequentes erosões e torna os ambientes aquáticos cada vez mais rasos (FACUNDES, 2000; QUEIROZ, 2007).

Esses fatores de impacto percebidos pelos Pescadores artesanais nas comunidades das duas bacias estudadas foram apontados também como responsáveis pela relação de causa e efeito na abundância de peixes, sendo registrada uma diminuição de espécies e espécimes de peixes segundo a percepção dos pescadores (Tabela 2).

Nos últimos anos, a redução de espécies no ambiente natural, frente aos impactos ambientais cada vez mais frequentes, tem gerado uma série de estudos de distribuição de espécies como preocupação central da ecologia. Logo, um número crescente de estudos em ecologia, biogeografia, biologia da conservação vem construindo modelos preditivos da distribuição das espécies visando a melhor proteção e gestão dos recursos naturais e dos ecossistemas (GUISAN \& ZIMMERMANN, 2000; THUILLER, 2003).

Ao analisar a abundância de peixes nas comunidades componentes das duas áreas de estudo segundo a percepção dos pescadores, foi possível notar que, mesmo com o cenário registrado de diminuição da abundância, algumas espécies apresentaram aumento em quantidade sob a ótica dos pescadores artesanais (Tabela 2). Esse registro de aumento de espécies de peixes segundo os pescadores já foi percebido e apontado também como sugestão de novos estudos em outras regiões da Amazônia e do mundo (SILVANO \& 
PANTOJA et al. Percepção de impactos sobre a pesca artesanal: caminhos para o manejo dos recursos pesqueiros do Amapá, Brasil. Ethnoscientia v.6 n. 1, 2021. DOI: 10.22276/ethnoscientia.v6i1.355

VALBO-JORGENSEN 2008; HALLWASS et al., 2013). No entanto, muitas das vezes essas análises de abundância dependem da análise de muitas variáveis (THOMPSON et al., 2001) entre as quais pode ser incluída a percepção ambiental conforme analisado nesse estudo. Na Bacia do Igarapé Fortaleza, os pescadores perceberam uma redução maior na diversidade e abundância de peixes (Tabela 2).

No entanto, os dados quantitativos obtidos sobre a percepção da redução da abundância são elevados tendo em vista que mais de 50\% dos pescadores perceberam essa alteração ambiental referente aos recursos pesqueiros. Dessa forma, o Conhecimento Ecológico Local dos pescadores apresentou informações importantes sobre o meio ambiente em que praticam a atividade pesqueira, correspondendo esse conhecimento a diversos aspectos ecológicos (Tabela 3). 


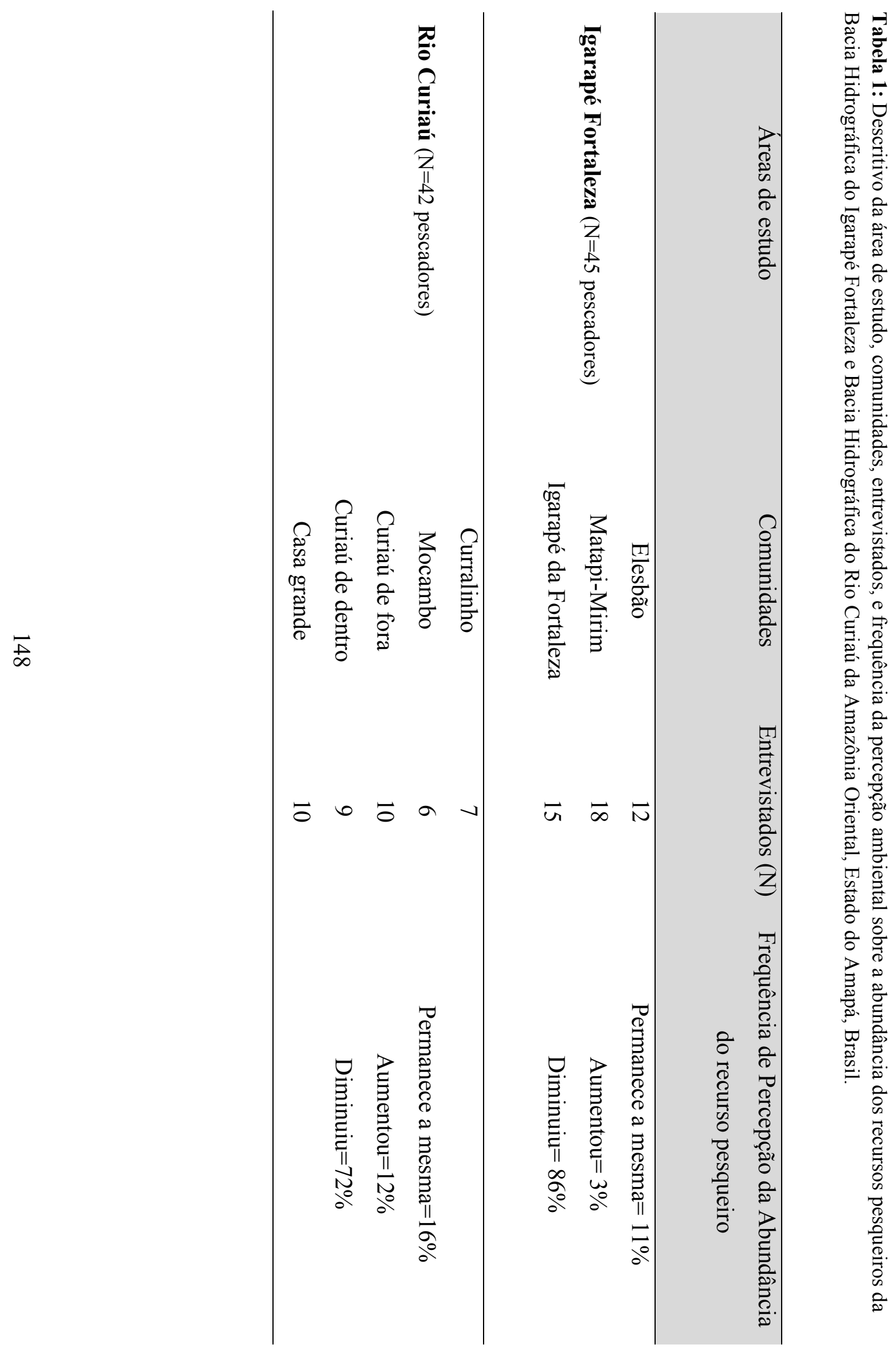




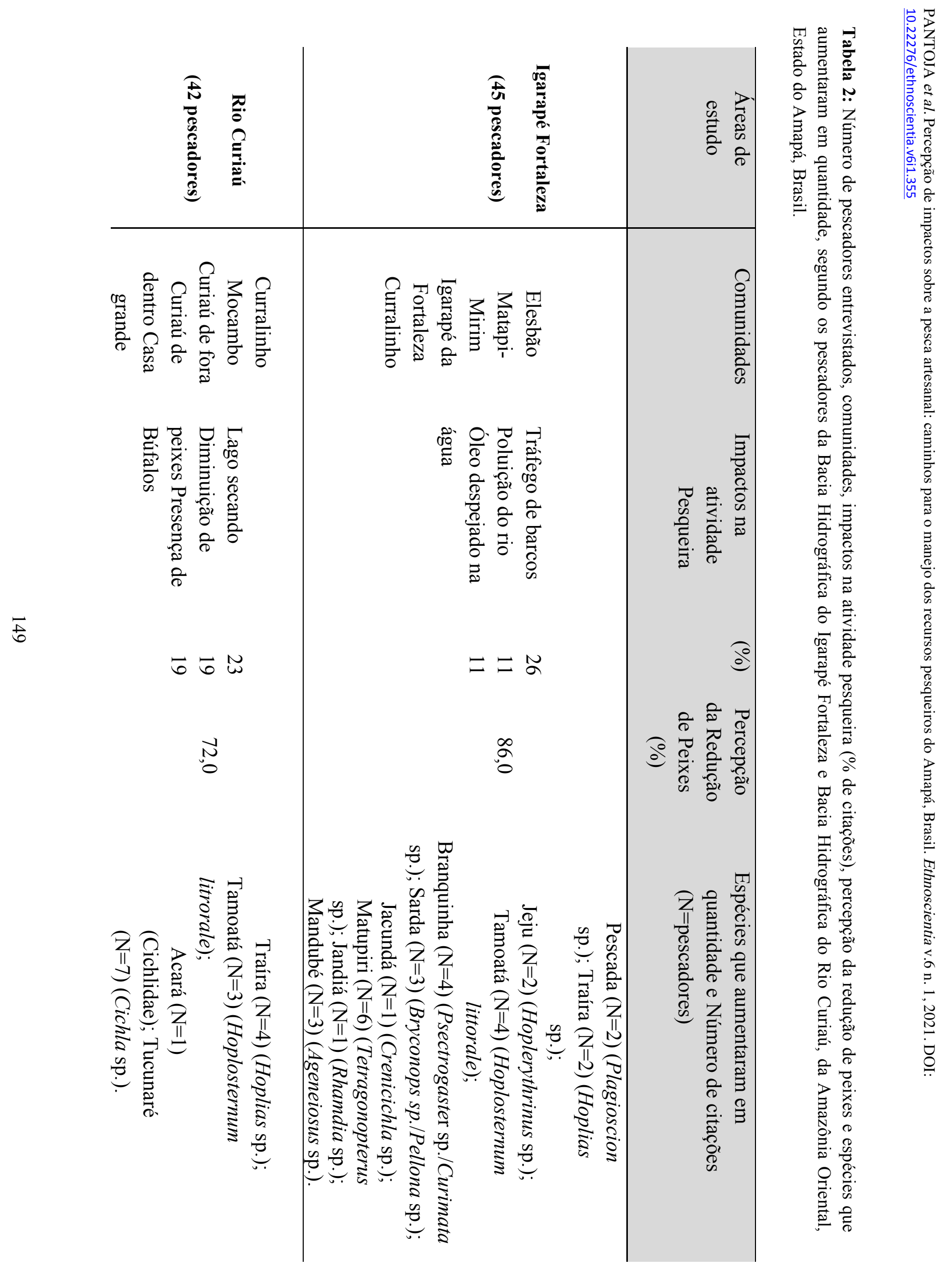




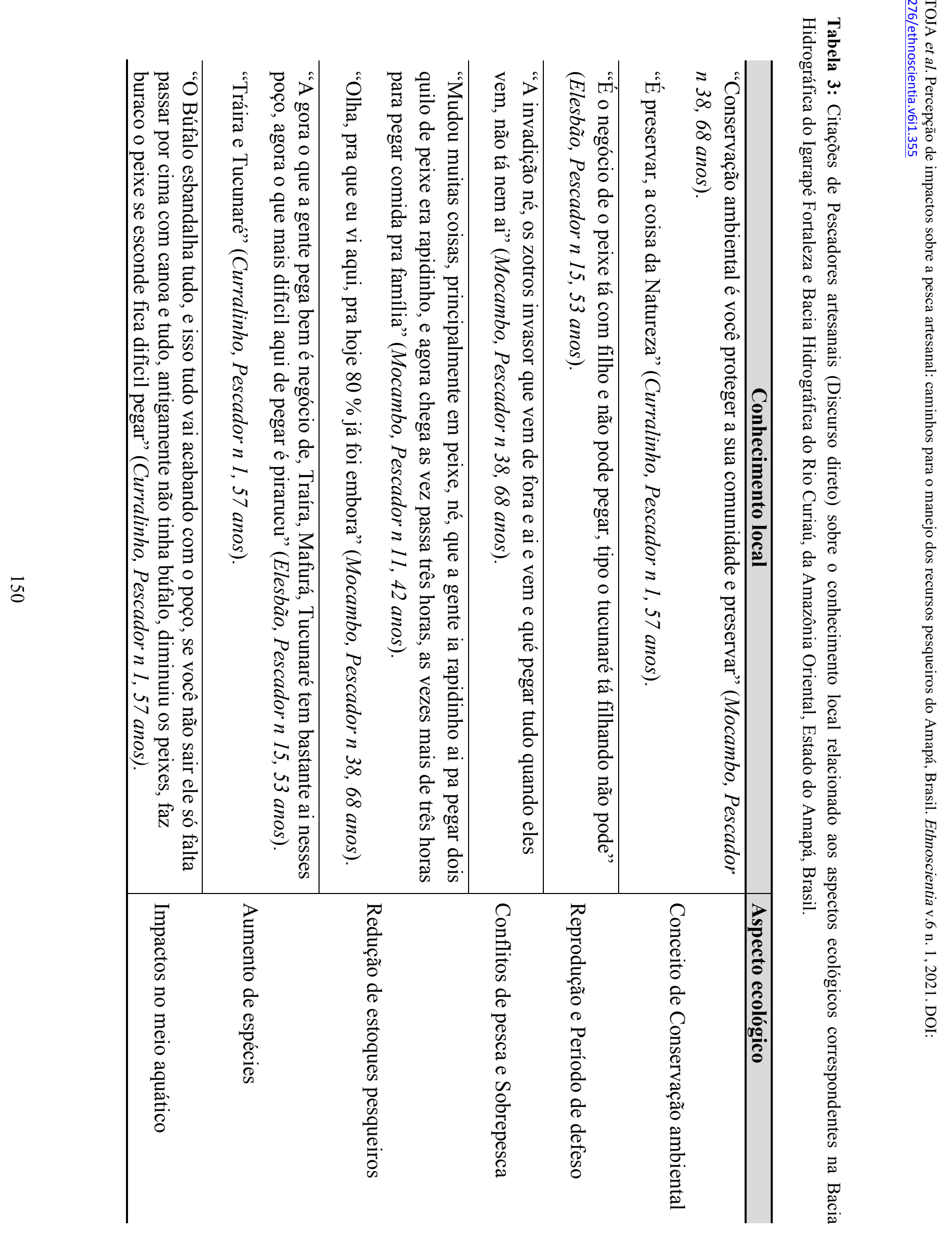


Quanto a percepção de impactos relacionada e alternativas para solução do problema, foi constatado muitos impactos relevantes à atividade pesqueira e uma extensa variedade de soluções, citadas pelos Pescadores, para a resolução dos problemas das áreas de pesca das comunidades componentes da Bacia Hidrográfica do Igarapé da Fortaleza (Tabela 4) e Bacia Hidrográfica do Rio Curiaú (Tabela 5). Nesse contexto, sabemos do papel fundamental das comunidades tradicionais para a preservação e conservação dos ecossistemas, sendo os pescadores artesanais, capazes de intervir na construção de um modelo sustentável de desenvolvimento apesar de muitas vezes serem excluídos socialmente dos processos deliberativos.

Dessa forma, tendo em vista a sensibilidade ambiental dessas populações, aliadas a grande quantidade de alternativas de mitigação dos impactos apontados por eles (Tabelas 4;5), a cogestão seria uma boa alternativa para conservação ambiental dessas áreas, pois sabemos que os pescadores artesanais não podem garantir a sua plena subsistência frente ao crescente processo de industrialização da pesca e do cenário de impactos no ecossistema aquático. As comunidades indígenas e quilombolas dependem da preservação da natureza como elemento de proteção dos seus valores culturais. Algumas políticas públicas de sucesso na conservação da biodiversidade relacionam-se diretamente pela integração de vários setores, incluindo as comunidades tradicionais em estratégias de gestão e cogestão, possibilitando uma ação interativa (DIAZ, 1994; DEMO, 1996; ACSELRAD, 2001; DIEGUES, 2002). 


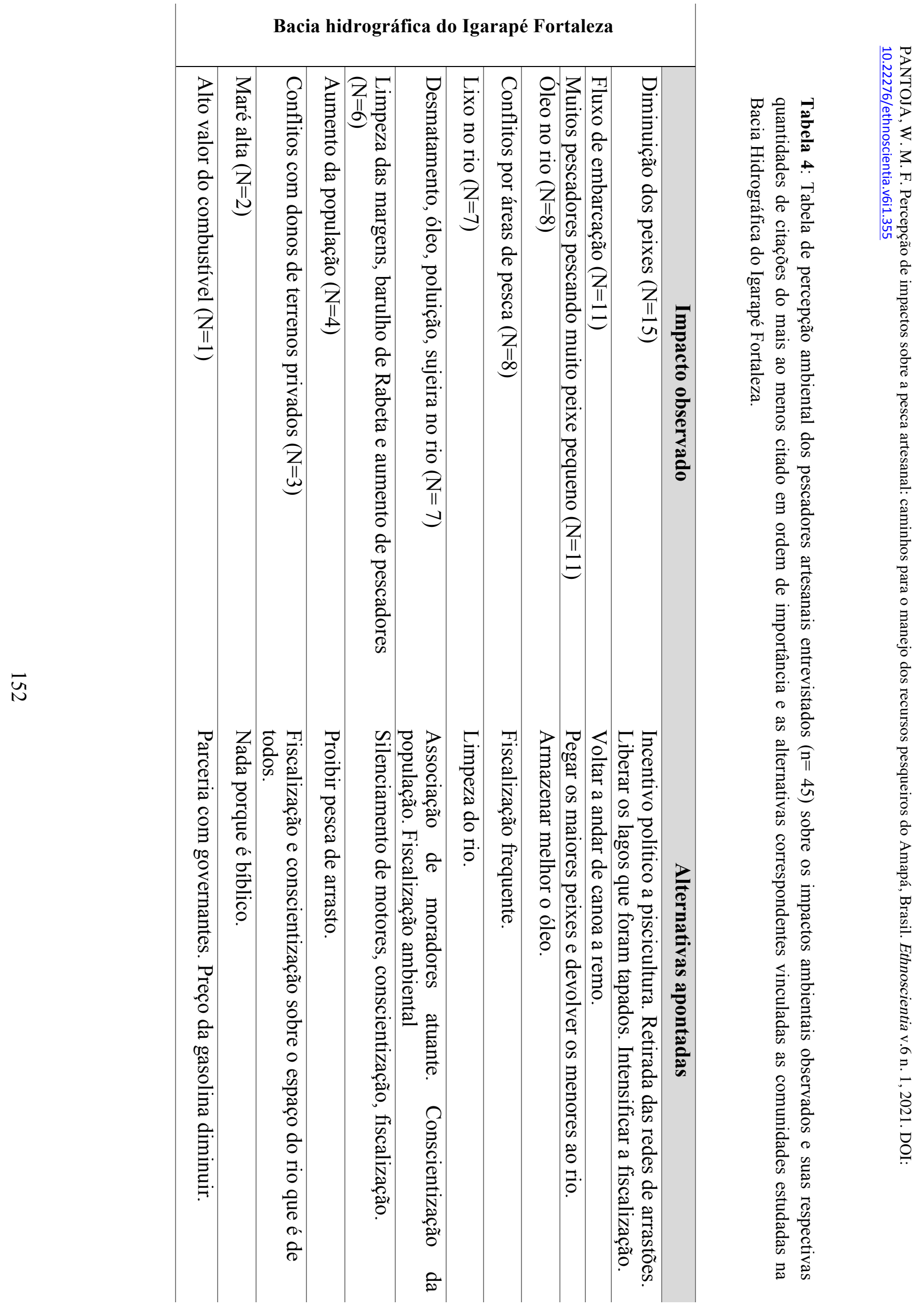




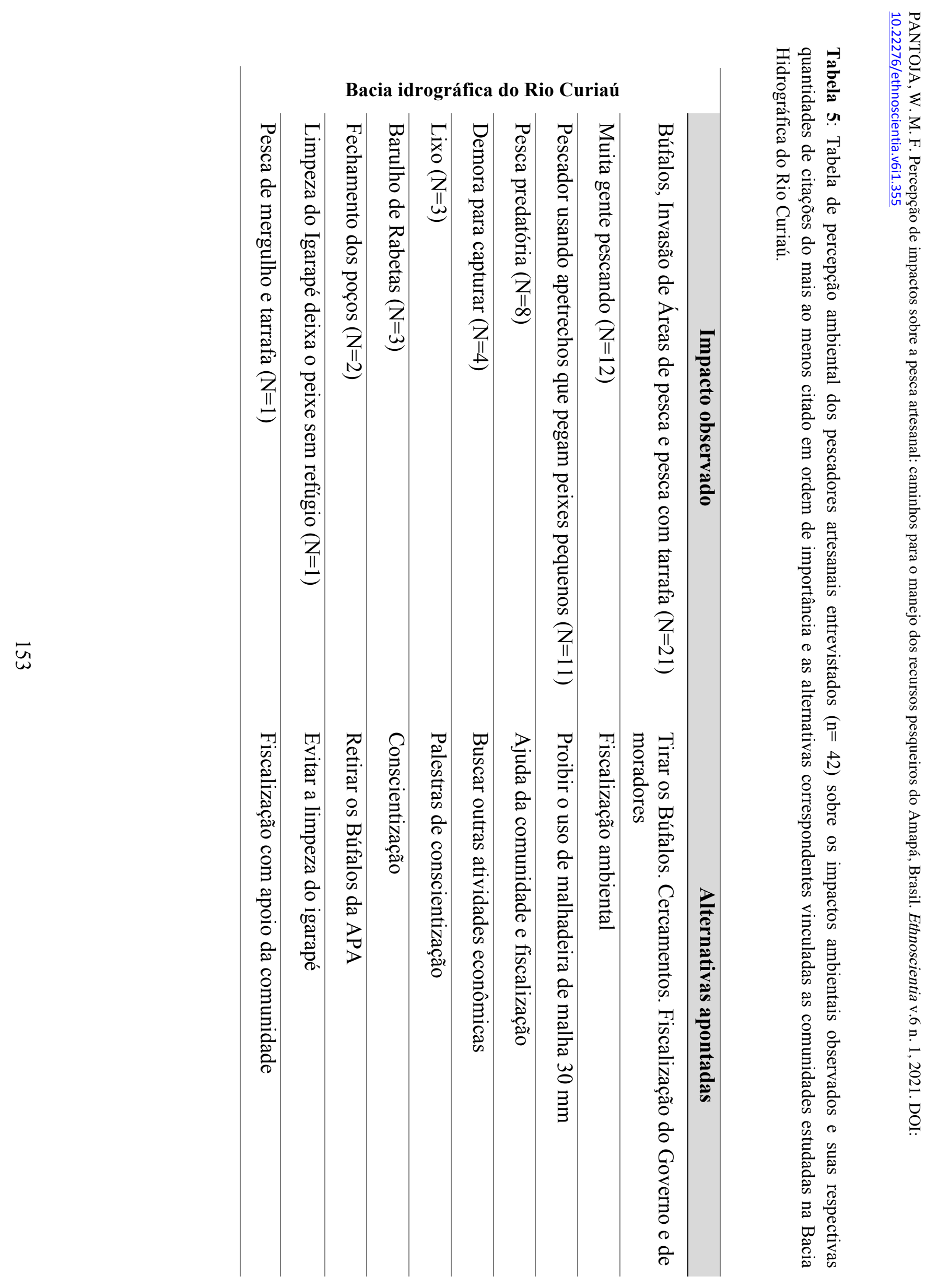


PANTOJA, W. M. F. Percepção de impactos sobre a pesca artesanal: caminhos para o manejo dos recursos pesqueiros do Amapá, Brasil. Ethnoscientia v.6 n. 1, 2021. DOI: 10.22276/ethnoscientia.v6i1.355

Nesse contexto, muitos estudos têm abordado a preocupação com os problemas relacionados aos impactos na atividade pesqueira citados pelos pescadores, sendo de extrema importância avaliar as particularidades de cada ecossistema e comunidades a fim de garantir medidas mitigadoras mais eficazes aliadas a cogestão dessas áreas (TUNDISI, 2003; SANTOS; SANTOS, 2005; AGOSTINHO et al., 2005; JUNK et al., 2007; PINHEIRO et al., 2013; CASTELLO et al., 2013; RODRIGUES et al., 2016).

Quanto a estratégia de gestão, 44,5\% dos pescadores entrevistados na B.H.I.F apontaram existir uma organização da comunidade para conservar os pesqueiros e para B.H.R.C, 72,5\% dos entrevistados apontaram mesma característica, o que para uma área mais preservada apresenta-se como ação positiva de organização comunitária em favor da conservação. Para as duas áreas de estudo $85 \%$ dos entrevistados apontaram a atitude de não pegar peixes em estágio reprodutivo e não pescar no período de defeso como sendo a estratégia utilizada por eles para manter os estoques. Nesse contexto, é evidente que esses dados decorrentes das respostas de percepção dos pescadores mostram que os usos e ações para a manutenção dos recursos naturais dizem muito sobre a capacidade de preservação e adaptação de uma determinada comunidade bem como mencionado e discutido por outros autores (CAFIERO et al., 2015).

No entanto, quanto ao conhecimento de leis especificas para conservação da pesca, nas duas áreas de estudo a porcentagem de pescadores que afirmaram conhecer leis especificas de proteção aos peixes e a pesca na B.H.I.F, foi $46,6 \%$ e nas comunidades da B.H.R.C foi $56,6 \%$. Com relação a opinião quanto à eficácia das leis os entrevistados afirmaram com maior frequência (76\%) que a lei é muito boa. No entanto, citaram também a necessidade de aperfeiçoamento e maior frequência de fiscalização dos órgãos competentes, bem como julgaram a atitude de apreensão dos apetrechos de pesca errada e desnecessária.

Contudo, esse estudo de percepção ambiental sob a ótica do pescador artesanal apresentou dados relevantes a partir do conhecimento ecológico local dessas populações, bem como foi possível verificar uma grande quantidade de impactos e principalmente boa vontade de indicar alternativas para que se possa intervir de maneira positiva, sendo relevantes citações como: "Pegar os maiores peixes e devolver os menores ao rio"; "Fiscalização e conscientização sobre o espaço do rio que é de todos"; "Fiscalização do Governo e de moradores"; "Buscar outras atividades econômicas e incentivo político a piscicultura, entre outros tabelados neste estudo e que apontam para a oportunidade de 
PANTOJA et al. Percepção de impactos sobre a pesca artesanal: caminhos para o manejo dos recursos pesqueiros do Amapá, Brasil. Ethnoscientia v.6 n. 1, 2021. DOI: 10.22276/ethnoscientia.v6i1.355

criação de um processo de gestão compartilhada entre as comunidades locais dessa região e o setor governamental responsável pela política pesqueira e conservação ambiental.

Estes dados do conhecimento de pescadores artesanais, podem orientar estudos futuros para coleta de peixes, mitigação de impactos e estratégias de educação ambiental, bem como podem servir para uma análise mais eficiente das estratégias já implementadas nas comunidades, fortificando-as, revisando-as e acrescentando ideias sustentáveis e sociambientalmente viáveis a essas populações locais. Avaliando e valorizando esse conhecimento local buscando resolver os problemas atuais e evitar impactos futuros na região.

\section{CONCLUSÃO}

Este estudo concluiu que há conhecimento considerável dos pescadores artesanais sobre aspectos ambientais da atividade pesqueira e os estes dados são pioneiros para a região.

Este estudo pode ajudar na conservação da pesca artesanal, se consultados pelos orgãos competentes. Assim, podem ser usados para resolver inúmeros impactos ambientais observados pelos pescadores, e podem ser considerados caminhos para a conservação dessas áreas no estado do Amapá, Brasil.

A percepção sobre a abundância e a diminuição de espécies de peixe nas duas áreas de estudo apresentou diferenças de acordo com as frequências apresentadas. Foi registrada a redução de estoques pesqueiros e o aumento de outras espécies nas comunidades componentes da bacia hidrográfica do Rio Curiaú e na bacia do Igarapé Fortaleza de acordo com o conhecimento ecológico local e que devem ser comprovados com pesquisas de manejo, ecologia e de espécies in loco.

\section{AGRADECIMENTOS}

Os autores são gratos ao Conselho Nacional de Pesquisa e Desenvolvimento Tecnológico (CNPQ), pela bolsa concedida ao Wanderson Michel da Farias PantojaPPGEAP-UFPA, bem como a equipe de pesquisa e aos pescadores que contribuíram com valiosas informações para a pesquisa. 
PANTOJA et al. Percepção de impactos sobre a pesca artesanal: caminhos para o manejo dos recursos pesqueiros do Amapá, Brasil. Ethnoscientia v.6 n. 1, 2021. DOI: 10.22276/ethnoscientia.v6i1.355

\section{REFERÊNCIAS BIBLIOGRÁFICAS}

ACSELRAD, H. Políticas ambientais e construção democrática. In: VIANA, G.; SILVA, M.; DINIZ, N. (Org.). O desafio da sustentabilidade: um debate socioambiental no Brasil. São Paulo: Editora Fundação Perseu Abramo, 2001. p. 75 $-131$.

AgOstinho, A. A.; THOMAZ, S. M.; GOMES, L. C. Conservação da biodiversidade em águas continentais do Brasil. Megadiversidade, v. 1, n. 1, 2005. p. 70-78.

ALBUQUERQUE, U.P.; LUCENA, R.F.P. Métodos e técnicas para coleta de dados. pp. 37-55. In: U.P. Albuquerque (org.). Métodos e técnicas na pesquisa etnobotânica. Recife, Editora NUPEEA. 2004.

AMOROZO, M. C. M. A abordagem etnobotânica na pesquisa de plantas medicinais. In: DI STASI, L. C. (Org.). Plantas medicinais: arte e ciência - um guia de estudo interdisciplinar. Botucatu: UNESP, 1996. p. 47-68.

ANDRADE, C.T.S., MARQUES, J.G.W. \& ZAPPI, D.C. Utilização de cactáceas por sertanejos baianos: tipos conexivos para definir categorias utilitárias. Sitientibus Ser. Ci. Biol. 6(Número Especial - Etnobiologia): 6-12. 2006.

BATISTA, V. S.; ISSAC, V. J.; VIANA, J. P. "Exploração e manejo dos recursos pesqueiros da Amazônia". Em RUFINO, M. L. (ed.). A pesca e os recursos pesqueiros na Amazônia brasileira. ProVárzea. Manaus, IBAMA, pp. 63-152, 2004. 268 p.

BAILEY, K. Methods of social research. New York, The Free Press. 1994.

BALÉE, W. Biodiversidade e os Índios Amazônicos. In: Amazônia, Etnologia e História Indígena. (E.V Castro \& M.C. Cunha org.) NHII /FAPESP. 1994. p. 383393.

BARBOZA, R.S. L.; PEZZUTI, J. C. B. Etnoictiologia dos pescadores artesanais da Resex Marinha Caeté- Taperaçu, Pará: aspectos relacionados com etologia, usos de hábitat e migração de peixes da família Sciaenidae. Sitientibus série Ciências Biológicas 11(2): 133-141. 2011.

BEGOSSI, A.; GARAVELLO, J. C. Notes on the ethnoicthyology of fishers from the Tocantins River (Brazil). Acta amazônica, 20:341-351. 1990.

BEGOSSI, A. Fishing spots and sea tenure: incipient forms of local management in Atlantic Forest coastal communities. Human Ecology, v. 23, 1995. p. 387-406.

BEGOSSI, A.; HANAZAKI, N.; RAMOS, R. Food chain and the reasons for food taboos in the Amazon and in the Atlantic Forest coast. Ecological applications, Washington, 14(5): 1334-1343. 2004.

BEGOSSI, A.; SILVANO, A. M. Ecology and ethnoecology of dusky grouper [garoupa, Epinephelus marginatus (Lowe, 1834)] along the coast of Brazil. Journal of 
PANTOJA et al. Percepção de impactos sobre a pesca artesanal: caminhos para o manejo dos recursos pesqueiros do Amapá, Brasil. Ethnoscientia v.6 n. 1, 2021. DOI: 10.22276/ethnoscientia.v6i1.355

Ethnobiology and Ethnomedicine, v. 4, n. 20. 2008. p. 1-14.

BELTRÃO, H.; PORTO-BRAGA, T. M.; SCHWARTZ-BENZAKEN, Z. Alternative bait usage during the piracatinga (Calophysus macropterus) fishery in the Manacapuru region, located at the lower Solimões-Amazonas River, Amazon basin, Brazil. PanAmerican Journal of Aquatic Sciences, 12(3): 194-205. 2017.

BERNARD, H.R. Research methods in antropology: qualitative and quantitative approaches. 4 ed. Lanham. Altamira, 2005.

CARDOSO, R.C.L. A Aventura Antropológica: Teoria e Pesquisa. Rio de Janeiro, Paz e Terra. 1986.

CASTELLO, L.; MCGRATH, D. G.; HESS, L. L.; COE, M. T.; LEFEBVRE, P. A.; PETRY, P. The vulnerability of Amazon freshwater ecosystems. Conservation Letters 1-13. 2013.

CAFIERO, C., BOBENRIETH, E.S.A., BOBENRIETH, J.R.A, WRIGHT, B.D., Maximum likelihood estimation of the standard commodity storage model. Evidence from sugar prices. American Journal of Agricultural Economics, 97, 122-136. 2015.

COSTA, R.G.S. e COLESANTI, M.M. A contribuição da percepção ambiental nos estudos de áreas verdes. RA'E GA-O Espaço Geográfico em Análise, 22: 238-251. 2011.

DEMO, P. Participação é conquista: noções de política social participativa. 3. ed. São Paulo: Cortez. 1996.

DIAZ, J. E. B. O que é participação. 8. ed. São Paulo: Brasiliense. 1994.

DIEGUES, A. C. S. Etnoconservação da natureza: enfoques alternativos. In: DIEGUES, A. C. (Org.). Etnoconservação: novos rumos para a conservação da natureza. 2. ed. São Paulo: Hucitec: NUPAUB - USP, 2002. p. 1 - 46.

DIEGUES, A. C. A pesca construindo sociedades. São Paulo: NUPAUB/USP. 315 p. 2004.

DORIA, CC; ARAÚJO, T R; SOUZA, ST B; VILARA, G T. Contribuição da etnoictiologia à análise da legislação pesqueira referente ao defeso de espécies de peixes de interesse comercial no oeste da Amazônia brasileira, Rio Guaporé, Rondônia, Brasil. Revista Biotemas, v. 21, n.2. 2008. p.119-132.

FACUNDES, F. S.; GIBSON, V. M. Recursos naturais e diagnóstico ambiental da APA do Rio Curiaú - Macapá: UNIFAP, 2000 - (Trabalho de Conclusão de Curso). 2000.58 p.

FAO. Diretrizes Voluntárias para garantir a pesca de pequena escala sustentável; No contexto da segurança alimentar e da erradicação da pobreza. Organizações das Nações Unidades para Alimentação e a Agricultura, Roma. 2017. 34 p. 
FERREIRA, M.F.N. e CARAMASCHI, E.P. Aspectos da estratégia reprodutiva de machos de Teleósteos na área de influência da Usina Hidrelétrica Serra da Mesa, Alto rio Tocantins, GO. In: NOGUEIRA, M.G.; HENRY, R.; JORCIN, A. (Eds.): Ecologia de reservatórios: impactos potenciais, ações de manejo e sistemas em cascata. São Carlos: Ed. RiMa. 2005. p.305-328.

FREITAS, C. E. C.; RIVAS, A. A. F. A pesca e os recursos pesqueiros na Amazônia Ocidental. Ciênc. cult. (São Paulo); 58(3):30-32, jul.-set. 2006.

FURTADO. L. G. Problemas Ambientais e Pesca Predatória na qualidade de vida na Amazônia: In:Furtado, Lourdes G. (org.) Amazônica, desenvolvimento Social, diversidade e qualidade de vida, UFRA, NUMA, BELÈM, p: 157-162. 1997.

GIL, A.C. Métodos e Técnicas de Pesquisa Social. 5a ed. São Paulo: Atlas, 208 p. 1999.

GUISAN, A. ZIMMERMANN, N. E. Predictive habitat distribution models in ecology. Ecol. Model. 135: 147.p186. 2000.

HALLWASS, G.; LOPES, P.F.; JURAS, A. A; SILVANO, A. M. Fishers knowledge identifies environmental changes and fish abundance trends in impounded tropical rivers. Ecological Applications, 23(2), pp. 392-407. 2013.

HALLWASS, G \& SILVANO, R. A. M. Etnoecologia e Pesca: influência de unidades de conservação e aplicação do conhecimento ecológico local de pescadores no manejo e conservação dos recursos pesqueiros no Baixo Rio Tapajós, Amazônia brasileira, (in press). 2015.

HALLWASS, G., \& SILVANO, R. A. M. Patterns of selectiveness in the Amazonian freshwater fisheries: implications for management. Journal of Environmental Planning and Management, 59(9), 1537-1559. 2016.

IEPA-Instituto de Pesquisas Científicas e Tecnológicas do Estado do Amapá, 2013.

ISAAC, V. J.; ROCHA, V. L. C.; MOTA, S. Considerações sobre a legislação da "piracema" e outras restrições da pesca da região do médio Amazonas. In: FURTADO, L. G.; LEITÃO, W.; MELO, A. F. de. Povos das águas: realidade e perspectiva na Amazônia. Belém: Museu Paraense Emílio Goeldi, p. 187-211. 1993.

ISAAC-NAHUM, V.J. Exploração e manejo dos recursos pesqueiros do litoral amazônico: um desafio para o futuro. Ciência e Cultura, 58:33-36. 2006.

ISAAC V. J.; ALMEIDA M. C. El consumo de pescado en la Amazonía brasileña. Fao/Copescal Documento Ocasional 13: 43. 2011.

IBGE. Pesquisa Nacional por amostra de domicílios: manual de entrevista. Brasília, DF:IBGE, Diretoria de Pesquisas, 366 p. 2014.

JOHANNES, R.E. Traditional marine conservation methods in Oceania and their demise. Annual Review of Ecology and Systematics 9:349-364. 1978. 
PANTOJA et al. Percepção de impactos sobre a pesca artesanal: caminhos para o manejo dos recursos pesqueiros do Amapá, Brasil. Ethnoscientia v.6 n. 1, 2021. DOI: 10.22276/ethnoscientia.v6i1.355

JOHNSON, L. M. Ethnobiology - Traditional Biological Knowledge in Contemporary Global Context. Anthropology 491 study guide, Athabasca University. p. 71. 2002.

JUNK, W.J.; SOARES, M.G.M.; BAYLEY, P.B. Freshwater fishes of the Amazon River basin: their biodiversity, fisheries, and habitats. Aquatic Ecosystem Health \& Management, Ontário, 10(2): 153-173. 2007.

KALIKOSKI, D. C. The Forum of the Patos Lagoon: an analysis o co- management arrangement for conservation of coastal resources in Southern Brazil. Vancouver, 257 p. Tese (Doutorado em Gestão Ambiental e de Recursos Naturais) - University British Columbia - UBC. 2002.

KALIKOSKI, D. C.; VASCONCELLOS, M. The role of fishers' knowledge in the comanagement of small-scale fisheries in the estuary of Patos Lagoon, Southern Brazil. In: HAGGAN, N.; NEIS, B.; BAIRD, I. G. (Ed.). Fishers' knowledge in fisheries science and management. Paris: UNESCO Publishing, p. 289-312. 2007.

MARQUES, J.G.W. Aspectos ecológicos na etnoictiologia dos pescadores do Complexo Estuarino-lagunar Mundaú-Manguaba. Campinas, (Doctoral Thesis in Ecology) - Universidade Estadual de Campinas. 1991.

MARQUES, J.G.W. Etnoictiologia: pescando pescadores nas águas da transdisciplinaridade. In: ENCONTRO BRASILEIRO DE ICTIOLOGIA, 11, 1995a, Campinas. Resumos. Campinas: Sociedade Brasileira de Ictiologia, p. 1-41. 1995a

MANESCHY, M. C. Ajuruteua: uma comunidade pesqueira ameaçada. Belém: UFPa. / CFCH. 1995.

MEIRELLES, P. R. de L.; MOCHIUTTI, S. Impactos Ambientais da Bubalinocultura nos Campos Inundáveis do Amapá. In: Workshop ECOLAB, 5. 2000, Macapá. Resumos. Macapá: IRD/UFPA/MPEG/IEPA, p. 57- 61. 2000.

MERONA, B de. "Pesca e ecologia dos recursos aquáticos na Amazônia". Em FURTADO, L., LEITÃO, W; MELO, F. (ed.). Povos das águas - realidade e perspectiva na Amazônia. Belém, MPEG/ UFPA, pp. 159-185, 292 p. 1993.

MELAZO, G.C. A percepção ambiental e educação ambiental: uma reflexão sobre as relações interpessoais e ambientais no espaço urbano. Olhares \& Trilhas, VI (6): 45 51. 2005.

MINAYO, M.C. O Desafio do Conhecimento: Pesquisa Qualitativa em Saúde. São Paulo - Rio de Janeiro, HUCITEC - ABRASCO, p. 105-196. 1992.

MINAYO, M.C.S. Pesquisa Social: Teoria, Método e Criatividade. Petrópolis: Vozes, 80 p. 1994.

MISUND, O. A.; KOLDING, J.; FRÉON, P. Fish capture devices in industrial and artisanal fisheries and their influence on management. In: HART, P. J. B.; REYNOLDS, J. D. Handbook of fish biology and fisheries - fisheries, v. 2, 2002. p. 13-36. 
PANTOJA et al. Percepção de impactos sobre a pesca artesanal: caminhos para o manejo dos recursos pesqueiros do Amapá, Brasil. Ethnoscientia v.6 n. 1, 2021. DOI: 10.22276/ethnoscientia.v6i1.355

MINISTÉRIO DO MEIO AMBIENTE. Diretrizes ambientais para o setor pesqueiro: diagnóstico e diretrizes para a pesca marítima. Brasília. 124p. 1997.

MORIN-LABATUT, G.; AKATAR, S. Traditional Knowledge: a resource to manage and share. Development 4:24-30. 1992.

MURRIETA, R. S. S.; BAKRI, M. S.; ADAMS, C.; OLIVEIRA, P. S. de S.; STRUMPF, R. Consumo alimentar e ecologia de populações ribeirinhas em dois ecossistemas amazônicos: um estudo comparativo. Revista de Nutrição, v. 21, p. 123 133. 2008.

NERI, S. H. A. A utilização das ferramentas de geoprocessamento para identificação de comunidades expostas a hepatite $\mathrm{A}$ nas áreas de ressacas dos municípios de Macapá e Santana/AP. 2004. 189 f. Dissertação (Mestrado) - Universidade Federal do Rio de Janeiro, Rio de Janeiró. 2004.

OLIVEIRA, K.A. e CORONA. H.M.P.A. Percepção ambiental como ferramenta de propostas educativas e de políticas ambientais. ANAP Brasil - Revista Científica, 1(1): 53-72. 2008.

PETRERE Jr., M. Pesca e esforço de pesca no Estado do Amazonas. II. Locais e aparelhos de captura e estatística de desembarque. Acta amazônica, 8 (Suplemento 2): 1-54. 1978.

PETRERE JR., M. Fishery ecology and management of the jaraqui (Semaprochilodus teaniurus, S. insignis) in Central Amazonia Regulated Rivers: Research and Management, 5:195-215. 1990.

PEZZUTI, J.C.B.; REBÊLO, G.H.; SILVA, D.F.; LIMA; J.P.; RIBEIRO, M.C. A caça e a pesca no Parque Nacional do Jaú. In: S.H. Borge, S. Iwanaga, C.C. Durigan \& M.R. Pinheiro (eds), Janelas para a Biodiversidade no Parque Nacional do Jaú: uma estratégia para o estudo da biodiversidade na Amazônia. Fundação Vitória Amazônica, Manaus, p. 123-230. 2004.

PINHEIRO, D. A.; TAVARES-DIAS, M.; DIAS, M. K. R.;SANTOS, E. F.; MARINHO, R. G. B. Primeiro registro da ocorrência de protozoários em tamoatá Hoplosternum littorale no Brasil. Boletim do Instituto de Pesca, v. 39, p. 169- 177. 2013.

POMEROY \& BERKES PY-DANIEL, L. H. R.; OLIVEIRA, E. C. Seven new species of Harttia from the Amazonian-Guyana region (Siluriformes: Loricariidae). Ichthyology Explorer Freshwaters. v. 12, n. 1, 2001. p. 79-96.

POSEY, D.A. Etnoecology as applied anthropology in Amazonian develop-ment. Hum. Organ. 43(2):95-107. 1984.

POSEY, D.A. Indigenous knowledge and development: an ideological bridge to the future. Ciência e Cultura, 35(7):18-24. 1983.

QUEIROZ, A. L. de; MACHADO, S. do A. Potencial de utilização madeireira de 
PANTOJA et al. Percepção de impactos sobre a pesca artesanal: caminhos para o manejo dos recursos pesqueiros do Amapá, Brasil. Ethnoscientia v.6 n. 1, 2021. DOI: 10.22276/ethnoscientia.v6i1.355

espécies florestais de várzea no município de Mazagão no estado do Amapá. Floresta, v. 37, n. 2, p. 293-302. 2007.

RODRIGUES, M. N. G.; DIAS, M. K. R.; MARINHO, R. G. B.; TAVARES-DIAS, M. Parasites diversity of Osteoglossum bicirrhosum, an Osteoglossidae fish from amazon. Neotropical Helminthology, vol. 8, n², jul-dec, pp. 383-391. 2014.

SANTOS, F. M. Lagoa dos Índios: Ecossistema Preservado, Qualidade de Vida Assegurada. 36 f. Dissertação (Mestrado em Gestão Ambiental) - Faculdade de Macapá, Macapá. 2006.

SANTOS, G.M; SANTOS, A.C.M. Sustentabilidade da pesca na Amazônia. Estudos avançados. 2005.

SEMA. Secretaria do Meio Ambiente do Amapá. Macapá: Instituto Brasileiro de Administração Municipal, 2013.

SEIXAS, C. S.; BEGOSSI, A. Ethnozoology of fishing communities from Ilha Grande (Atlantic Forest Coast, Brazil). Journal of Ethnobiology , v.21, n. 1, p. 107135. 2001.

SILVA, L. M. A.; LOPES, E.; AGUIAR, J. S; SANTOS, V. F. Situação da pesca no setor estuarino. In: DIAGNÓSTICO Sócio-Ambiental Participativo do Setor Costeiro Estuarino do Estado do Amapá. Macapá: IEPA, p. 104 - 114. 2004.

SILVA, L. M. A. da; SILVA, S. L. de F. A atividade pesqueira na região atlântica da costa do Amapá: Município de Amapá, Pracuúba, Tartarugalzinho e baixo Araguari. In: Rede Cooperativa de Monitoramento Ambiental de Áreas sob Influência da Industria Petrolífera. Natal: CT-PETRO, p. 173-187. 2006.

SILVA, L. M. A.; TAVARES-DIAS, M. A pesca artesanal no estado do amapá: estado atual e desafios. Bol. Téc. Cient. Cepnor, v. 10, n. 1, p: $43-53.2010$.

SILVA, L.M. A. da. Composição, estrutura e distribuição da ictiofauna do rio Matapi, Estado do Amapá. / Luis Mauricio Abdon da Silva; orientador Marcos Tavares Dias. Macapá (Tese de Doutorado). 2014.

SILVANO, R. A. M; BEGOSSI, A. Seasonal dynamics of fishery at the Piracicaba River (Brazil). Fisheries Research, Amsterdã, n. 51. 2001. p. 69-86.

SILVANO, R.A. M; BEGOSSI, ALPINA. Ethnoichthyology and fish conservation in the piracicaba river (brazil). Nucleo de estudos e Pesquisas Ambientais, University of Campinas, Brazil. Journal of Ethnobiology. 2002.

SILVANO, R. A. M. Pesca artesanal e etnoictiologia. In: BEGOSSI, A. Ecologia de pescadores da Mata Atlântica e da Amazônia. São Paulo: HUCITEC, NEPAM/UNICAMP, NUPAUB/USP, FAPESP. p. 187-222. 2004.

SILVANO, R. A. M; SILVA, A.L; CERONI, M.; BEGOSSI, A. Contributions of ethnobiology to the conservation of tropical rivers and streams. Aquatic Conserv: 
PANTOJA et al. Percepção de impactos sobre a pesca artesanal: caminhos para o manejo dos recursos pesqueiros do Amapá, Brasil. Ethnoscientia v.6 n. 1, 2021. DOI: 10.22276/ethnoscientia.v6i1.355

Mar. Freshw. Ecosyst. 18: 241-260. 2008.

SILVANO, R. A. M; VALBO-JORGENSEN, J. Beyond fishermen's tales: contributions of fishers' local ecological knowledge to fish ecology and fisheries management. Environ Dev Sustain 10:657-675. 2008.

SILVANO, R. A. M; BEGOSSI. A Fishermen's local ecological knowledge on Southeastern Brazilian coastal fishes: contributions to research, conservation, and management. Neotropical Ichthyology, 10(1): 133-147. 2012.

SUPERINTENDENNCIA DA ZONA FRANCA DE MANAUS - SUFRAMA. Potencialidades regionais estado do Amapá. 56p. 1999.

SCHREIBER, D. K. Co-management without involvement: the plight of fishing communities. Fish and fisheries, v. 2, p. 376-384. 2001.

TAKIYAMA, L.R.; SILVA, A.Q. Diagnóstico das Ressacas do estado do Amapá: Bacias do Igarapé da Fortaleza e Rio Curiaú, Macapá-AP: GEA/SETEC/IEPA, 255pp. 2004.

THOMPSON, P.M.; VIDAL, D.C, GIEDD, J.N. Mapping adolescent brain change reveals dynamic wave of accelerated gray matter loss in very early-onset schizophrenia. Proc Natl Acad Sci USA.; 98:11650-5. 2001.

THUILLER W. BIOMOD-optimizing predictions of species distributions and projecting potential future shifts under global change. Glob Change Biol 9:13531362. 2003.

TUNDISI, J. G. Água no século XXI: enfrentando a escassez. São Paulo: RiMa/IIE, 248 p. 2003.

WESTER, L; YONGVANIT, S. Biological diversity and community lore in northeastern Thailand. Journal of Ethnobiology 15:71-88. 1995.

WILSON, D. C.; NIELSEN, J. R.; DENGBOL, P. The fisheries co-management experience: accomplishments, challenges and prospects. London: Kluwer Academic Publishers. p. 348. 2003.

VIERTLER, R. B. Métodos antropológicos como ferramenta para estudos em etnobiologia e etnoecologia. In: Amorozo, M. C. M.; Ming, L. C.; Silva, S. P. (Org.) Métodos de coleta e análises de dados em etnobiologia, etnoecologia e disciplinas correlatas. CNPq, UNESP. 2002.

ZAPPES, C, A; A.; ALVES, L.C.P.; SILVA, C.V.; AZEVEDO, A.F.; DI BENEDITTO, A.P.M.; ANDRIOLO, A. Accidents between artisanal fisheries and cetaceans on the Brazilian coast and Central Amazon: Proposals for integrated management. Ocean \& Coastal Management 85 46-57. 2013.

ZAR, J. H. Biostatistical analysis. 5th ed. Prentice Hall, New Jersey, 944 pp. 2010. 